\title{
Análise da estrutura produtiva da economia paranaense sob um enfoque regional
}

Ronaldo Bulhões*

RESUMO - O principal objetivo deste trabalho é analisar a estrutura produtiva da economia do Paraná bem como sua distribuição regional. Para tal, utilizou-se como método de análise a estatística descritiva. Os resultados mostraram que, apesar da concentração industrial na região metropolitana de Curitiba, a agroindústria paranaense se apresenta como fator de sustentação de grande parte das atividades econômicas do interior do Estado.

Palavras-chave: Economia paranaense. Desenvolvimento regional. Agroindústria paranaense.

\section{INTRODUÇÃO}

O processo de reestruturação ocorrido no Paraná, sobretudo na década de 1990, refletiu na participação dos vários segmentos na composição do Valor Adicionado Fiscal (VAF) do Estado. Por exemplo, os segmentos de material de transporte, papel e papelão, embalagens plásticas (especialmente carnes e laticínios) e química (principalmente, fertilizantes e defensivos) registraram significativos avanços. Por outro lado, os segmentos como minerais não-metálicos, mecânica, têxtil, bebidas, produtos alimentares, entre outros, mantiveram-se ou perderam participação na composição do VAF (OLIVEIRA, 2003; CUNHA et. al., 2003).

Além do VAF, a reestruturação produtiva afetou, também, a distribuição da mão-deobra ocupada nos principais setores da economia paranaense (agropecuária, indústria, comércio e serviços) assim como na dinâmica das regiões do Estado. Sendo assim, nas seções seguintes serão discutidos (i) as transformações recentes ocorridas na estrutura produtiva na economia paranaense, bem como (ii) a distribuição regional da indústria e agroindústria paranaense com base no VAF, utilizando-se dados e estudos realizados pelo IPARDES. O período considerado foi a década de 1990, pelo fato da distribuição regional do parque agroindustrial paranaense, praticamente, não se ter alterado entre 2000 e 2008. Para ambos os casos, o critério de análise foi a comparação do produto, segmento, área e região, em relação ao Estado do Paraná.

\footnotetext{
* Doutor em Economia Aplicada pela UNICAMP. É professor do Curso de Economia da UNIOESTE/Cascavel e membro do Grupo de Pesquisa em Economia Aplicada (GPEA). Endereço eletrônico: ronaldobulhoes@unioeste.br
} 


\section{CONSIDERAÇÕES SOBRE AS TRANSFORMAÇÕES RECENTES OCORRIDAS NA ECONOMIA PARANAENSE}

O processo de desenvolvimento regional do Paraná contou com o apoio de várias organizações estatais, como: a Companhia de Desenvolvimento do Paraná (CODEPAR), o Banco de Desenvolvimento do Paraná (BADEP), o Banco do Estado do Paraná (BANESTADO), o Banco Regional de Desenvolvimento do Extremo Sul (BRDE), a Companhia Paranaense de Energia (COPEL), a Companhia de Saneamento do Paraná (SANEPAR), dentre outras. Ao mesmo tempo, entidades privadas como Hermes Macedo, Móveis Cimo, Prosdócimo, Grupo Bamerindus, Batavo, Cooperativa dos Cafeicultores e Agropecuaristas de Maringá (COCAMAR) e a Cooperativa Agropecuária Mourãoense (COAMO) também deram sua contribuição (LOURENÇO, 2000).

Esses órgãos, em datas diferentes, criaram uma base estrutural, sobretudo, na infra-estrutura de ciência e tecnologia, transportes, energia e telecomunicações, que passaram a desempenhar seu papel no desenvolvimento da economia paranaense ainda na década de 1960, com o objetivo de superar a fragilidade interna buscando a integração do Estado com investimentos pesados em infra-estrutura. Assim, na década de 1970, aproveitando a condição favorável de crescimento acelerado da economia brasileira, ocorreu a modernização agrícola e agroindustrial do Estado e a implantação da Cidade Industrial de Curitiba (CIC). O interior do Estado recebeu investimentos naqueles setores que ofereciam melhores condições de atração e desenvolvimento, principalmente os complexos agroindustriais, cuja estrutura industrial tradicional (produtos alimentares - café, cereais e afins - e madeireiro) sofreu modificações, cedendo espaço para outros produtos (soja, cana-de-açúcar, milho, refino de óleos vegetais, produção de rações, abate de animais - frangos e suínos - têxtil, fécula, entre outros) (BULHÕES, 2007).

O Paraná conseguiu, até meados da década de 1980, promover uma rápida e diversificada industrialização. No entanto, a partir de meados dessa década, em função da conjuntura econômica nacional e internacional desfavorável, esgota-se a capacidade de realização de investimentos produtivos por parte do setor público, momento em que o Estado entra em um processo de privatização (de bancos, rodovias, portos, telefonia, entre outros) que se acentua na década de 1990. No bojo desses acontecimentos, o setor industrial paranaense passou por um importante ajuste estrutural, sobretudo na década de 1990.

O ambiente acima delineado resultou na importância que o setor agropecuário obteve na conformação do VAF paranaense. Na verdade, até a metade da década de 1970, a agropecuária superava a indústria na participação do VAF estadual. A partir de 2000, de 
acordo com dados do IPARDES (2008), a agropecuária retoma o crescimento, aumentando a participação no VAF estadual (passando de 13,0\% em 2000 para 19,7\% em 2003), ao mesmo tempo em que o setor de serviços sofre uma redução (passou de 45,0\% em 2000 para 40,4\% em 2003) ficando nos mesmos patamares da indústria, que passou de 41,3\% em 2000 para 39,9\% em 2003. Ressalte-se que a forte reação da agropecuária em 2002-2003 decorreu dos efeitos positivos da combinação entre expansão da economia mundial, elevação das cotações das commodities e câmbio desvalorizado.

\section{DISTRIBUIÇÃO REGIONAL DA INDÚSTRIA E AGROINDÚSTRIA PARANAENSE}

Em termos regionais, 87,3\% do VAF da indústria de transformação paranaense está concentrada em três mesorregiões: Região Metropolitana de Curitiba (RMC), 64,5\%; Mesorregião Norte Central: 11,6\%; e Mesorregião Centro Oriental: 10,9\% (Tabela 1).

Por sua vez, apesar de haver uma pauta com diferentes segmentos industriais de transformação no Estado do Paraná, aproximadamente, 90,0\% do VAF industrial do Estado estão concentrados em cinco agrupamentos, a saber: metalmecânica; química; madeira; alimentos e bebidas; e vestuário, têxtil e couros.

TABELA 1 - NÚMERO DE ESTABELECIMENTOS INDUSTRIAIS, PARTICIPAÇÃO EM EMPREGOS E PARTICIPAÇÃO NO VALOR ADICIONADO ESTADUAL SEGUNDO MESORREGIÕES PARANAENSES: 1990/1995/2000

\begin{tabular}{|c|c|c|c|c|c|c|c|c|c|}
\hline \multirow{2}{*}{ Mesoregiões } & \multicolumn{3}{|c|}{ Estabelecimentos (abs) } & \multicolumn{3}{|c|}{ Empregos (\%) } & \multicolumn{3}{|c|}{ VAF ( $\%)$} \\
\hline & 1990 & 1995 & 2000 & 1990 & 1995 & 2000 & 1990 & 1995 & 2000 \\
\hline Noroeste & 778 & 996 & 1.520 & 3,26 & 6,06 & 6,57 & 1,65 & 2,08 & 2,17 \\
\hline Centro Ocidental & 347 & 361 & 420 & 1,66 & 1,94 & 1,64 & 2,00 & 0,82 & 0,67 \\
\hline Norte Central & 2.753 & 3.251 & 4.491 & 19,62 & 22,92 & 23,32 & 15,14 & 12,73 & 11,63 \\
\hline Norte Pioneiro & 516 & 534 & 676 & 3,77 & 3,18 & 3,40 & 3,07 & 1,58 & 1,41 \\
\hline Centro Oriental & 634 & 844 & 999 & 8,59 & 8,29 & 7,14 & 6,44 & 10,11 & 10,87 \\
\hline Oeste & 1.187 & 1.417 & 1.927 & 6,07 & 6,64 & 7,85 & 5,08 & 4,14 & 3,24 \\
\hline Sudoeste & 602 & 699 & 908 & 3,52 & 3,23 & 4,24 & 1,19 & 1,67 & 1,48 \\
\hline Centro-Sul & 550 & 681 & 872 & 4,78 & 4,01 & 4,16 & 3,57 & 2,78 & 1,93 \\
\hline Sudeste & 653 & 827 & 969 & 4,48 & 4,50 & 4,51 & 1,85 & 2,06 & 2,08 \\
\hline RMC & 4.833 & 5.235 & 6.151 & 44,26 & 39,24 & 37,16 & 60,01 & 62,04 & 64,52 \\
\hline Total & 12.853 & 14.845 & 18.933 & 100,00 & 100,00 & 100,00 & 100,00 & 100,00 & 100,00 \\
\hline
\end{tabular}

Os segmentos de metalmecânica e química estão concentrados na RMC (88,7\% e $82,1 \%$, respectivamente) e Mesorregião Norte Central (6,5\% e 10,5\%, respectivamente). Na verdade, os cinco agrupamentos estão fortemente concentrados na RMC. No interior do Estado, a mesorregião Norte Central é a grande concentradora desses segmentos. Já os segmentos de madeira, alimentos e bebidas e vestuário, têxtil e couros, estão distribuídas 
espacialmente em cinco mesorregiões, demonstrando uma menor concentração. Mesmo assim, o segmento de madeira está concentrado (79,4\% do VAF do segmento) em três mesorregiões próximas (RMC, mesorregiões Centro Oriental e Centro Sul) o que significa um aproveitamento de sinergias existentes entre a produção, processamento, disponibilidade de infra-estrutura, etc.

TABELA 2 - DISTRIBUIÇÃO ESPACIAL DOS PRINCIPAIS AGRUPAMENTOS DA INDÚSTRIA PARANAENSE EM PERCENTUAL DO VAF NO ANO DE 2000

\begin{tabular}{l|r|r|r|r|r}
\hline Mesorregião & Metalmecânica & Química & Madeira & $\begin{array}{c}\text { Alimentos e } \\
\text { bebidas }\end{array}$ & $\begin{array}{c}\text { Vestuário, } \\
\text { têxtil e couros }\end{array}$ \\
\hline Noroeste & - & - & - & - & 19,2 \\
Norte Central & 6,5 & 10,5 & 8,3 & 21,9 & 23,3 \\
Centro Oriental & - & - & 41,2 & 14,8 & - \\
Oeste & - & - & - & 15,7 & - \\
Centro Sul & - & - & 9,1 & - & - \\
RMC & 88,7 & 82,1 & 29,1 & 27,5 & 45,9 \\
Demais mesorregiões & 4,8 & 7,4 & 12,3 & 20,1 & 11,6 \\
Total & 100,0 & 100,0 & 100,0 & 100,0 & 100,0 \\
\hline
\end{tabular}

FONTE: (IPARDES, 2003). Dados trabalhados pelo autor.

Em 2000, cinco municípios concentravam 62,0\% do VAF da indústria de transformação do Estado: Araucária (RMC, com 23,4\%), Curitiba (RMC com 19,8\%), São José dos Pinhais (RMC com 9,5\%), Ponta Grossa (mesorregião Centro Oriental, com 5,6\%) e Londrina (mesorregião Norte Central com 3,5\%). Ressalta-se que uma única indústria (Petrobrás) é a responsável pela maior fonte de agregação de valor em Araucária, fazendo com que ela fique na frente de Curitiba em termos de VAF (IPARDES, 2003).

A estrutura agroindustrial do Estado, mesmo diversificada, possui 45,0\% de concentração em cinco agrupamentos: óleos e gorduras vegetais, que apesar de ter sofrido uma redução na década de 1990, é a principal atividade com 11,4\% do VAF do Estado; em segundo lugar vem o grupo de bebidas com 9,5\% do VAF; em seguida vêm a destilação de álcool e a produção de açúcar e adoçantes naturais, com 8,1\% do VAF; abate de aves e preparação de carnes e subprodutos com $8,1 \%$ e, por último, o abate de bovinos e suínos e preparação de carnes e subprodutos com 7,8\% (IPARDES, 2003).

A distribuição espacial das agroindústrias nem sempre coincide com a dinâmica regional de uma determinada atividade. Um exemplo característico é o de processamento de gordura e óleos vegetais, que têm $19,2 \%$ e 45,9\% da capacidade de processamento concentradas nas mesorregiões Centro Oriental e Metropolitana de Curitiba, sendo que nestas mesorregiões a produção de soja é pouco expressiva em relação às demais mesorregiões do 
Estado. No caso da mesorregião Norte Central, a localização das agroindústrias está próxima da matéria-prima.

TABELA 3 - DISTRIBUIÇÃO ESPACIAL DOS PRINCIPAIS AGRUPAMENTOS DA AGROINDÚSTRIA PARANAENSE EM PERCENTUAL DO VAF NO ANO DE 2000

\begin{tabular}{lr|r|r|r|r} 
Mesorregião & $\begin{array}{c}\text { Produto } \\
\text { Óleos e gorduras } \\
\text { vegetais }\end{array}$ & $\begin{array}{c}\text { Cervejas, } \\
\text { chope e malte }\end{array}$ & $\begin{array}{c}\text { Álcool e } \\
\text { açúcar }\end{array}$ & $\begin{array}{c}\text { Abate de } \\
\text { aves }\end{array}$ & $\begin{array}{c}\text { Abate de bovinos } \\
\text { e suínos }\end{array}$ \\
\hline Noroeste & - & - & 45,1 & - & - \\
Norte Central & 23,3 & - & 28,7 & 25,9 & 6,7 \\
Norte Pioneiro & - & - & 21,2 & - & - \\
Centro Oriental & 19,2 & 49,4 & - & - & 19,5 \\
Oeste & - & - & - & 23,8 & 63,5 \\
Sudoeste & - & - & - & 30,0 & - \\
RMC & 45,9 & 48,7 & - & - & - \\
Demais mesos & 11,6 & 1,9 & 5,0 & 23,3 & 10,3 \\
Total & 100,0 & 100,0 & 100,0 & 100,0 & 100,0 \\
\hline
\end{tabular}

FONTE: IPARDES (2003). Dados trabalhados pelo autor.

As mesorregiões Norte Central, Norte Pioneiro e Noroeste são responsáveis por 95,0\% da produção de álcool e açúcar do Estado. Assim como a RMC possui o núcleo forte da indústria paranaense, a mesorregião Norte Central se caracteriza por concentrar os quatro principais agrupamentos agroindustriais do interior do Estado. Por sua vez, as mesorregiões Oeste e Sudoeste são as principais responsáveis pelo abate de aves, suínos e bovinos do Paraná.

Em 2000, dez municípios concentravam 54,0\% do VAF da agroindústria do Estado: Curitiba (RMC com 12,1\%), Ponta Grossa (mesorregião Centro Oriental com 11,3\%), Toledo (mesorregião Oeste com 5,3\%), Maringá (mesorregião Norte Central com 5,2\%), Apucarana (mesorregião Norte Central com 4,3\%), Londrina (mesorregião Norte Central com 4,3\%), Paranaguá (RMC com 3,6\%), Cascavel (mesorregião Oeste com 2,8\%), Carambeí (mesorregião Centro Oriental com 2,7\%) e Araucária (RMC com 2,4\%) (IPARDES, 2003).

A distribuição regional da indústria e da agroindústria sugere que as plantas estejam próximas da fonte de matéria prima. $\mathrm{Na}$ verdade, a lógica econômica aponta para a especificidade do produto que se está industrializando. Para o caso de produtos perecíveis a indústria deve estar próxima da fonte de matéria-prima (como é o exemplo dos derivados de leite, legumes etc.) ou ainda, aquelas cujo transporte do produto beneficiado seja mais prático e barato (por exemplo, a cana e o minério de ferro). Por outro lado, existem aqueles produtos cuja planta não precisa necessariamente estar próxima da fonte. Um caso típico é o de processamento de soja, porém, existem outros, como a mandioca, o têxtil e o café, entre outros. 
$\mathrm{Na}$ verdade, a intensidade do reflexo de eventual crise será sentida, também, em função de como se encontram distribuídos os lucros da produção/comercialização entre os segmentos da economia (agropecuária, indústria e serviços). As análises apresentadas anteriormente permitiram conhecer como se encontra distribuída a produção/agroindustrialização do Estado. Complementando tal conhecimento a Tabela 4 apresenta a concentração da população, o grau de urbanização e a participação da renda nas mesorregiões.

TABELA 4 - NÚMERO DE MUNICÍPIOS, GRAU DE URBANIZACÃO, POPULACÃO, TAXA DE CRESCIMENTO DA POPULAÇÃO E GRAU DE OCUPAÇÃO SEGUNDO MESORREGIÕES PARANAENSES: 2000

\begin{tabular}{|c|c|c|c|c|c|c|c|c|c|}
\hline \multirow{2}{*}{ Mesorregião } & \multirow{2}{*}{$\begin{array}{l}\text { Número de } \\
\text { municípios }\end{array}$} & \multirow{2}{*}{$\begin{array}{c}\text { Grau de } \\
\text { urbanização }\end{array}$} & \multirow{2}{*}{ População } & \multirow{2}{*}{$\begin{array}{c}\text { Taxa Cresc. } \\
\text { pop. total } \\
1991-2000 \\
(\% \text { aa }) \\
\end{array}$} & \multirow{2}{*}{ Ocupados } & \multicolumn{4}{|c|}{$\begin{array}{l}\text { Distribuição dos } \\
\text { ocupados (\%) }\end{array}$} \\
\hline & & & & & & Agrop. & Ind. & Com. & Serv. \\
\hline Noroeste & 61 & 77,3 & 641.084 & $-0,25$ & 281.098 & 30,9 & 21,3 & 14,8 & 32,4 \\
\hline $\begin{array}{l}\text { Centro } \\
\text { Ocidental }\end{array}$ & 25 & 72,6 & 346.648 & $-1,24$ & 136.180 & 33,0 & 15,4 & 16,4 & 34,7 \\
\hline $\begin{array}{l}\text { Norte } \\
\text { Central }\end{array}$ & 79 & 88,4 & 1.829 .068 & 1,24 & 808.455 & 16,3 & 24,5 & 18,3 & 40,0 \\
\hline $\begin{array}{l}\text { Norte } \\
\text { Pioneiro }\end{array}$ & 46 & 75,1 & 548.190 & $-0,15$ & 226.805 & 36,6 & 17,3 & 13,2 & 32,6 \\
\hline $\begin{array}{l}\text { Centro } \\
\text { Oriental }\end{array}$ & 14 & 81,2 & 623.356 & 1,46 & 227.658 & 18,9 & 24,9 & 16,1 & 37,7 \\
\hline Oeste & 50 & 81,6 & 1.138 .582 & 1,28 & 494.716 & 20,8 & 18,8 & 19,9 & 38,6 \\
\hline Sudoeste & 37 & 59,9 & 472.626 & $-0,13$ & 222.635 & 42,1 & 17,3 & 13,1 & 26,9 \\
\hline Centro Sul & 29 & 60,9 & 533.317 & 0,69 & 210.358 & 38,6 & 19,3 & 12,7 & 28,6 \\
\hline Sudeste & 21 & 53,6 & 377.274 & 0,89 & 160.854 & 47,1 & 19,1 & 9,9 & 23,0 \\
\hline RMC & 37 & 90,6 & 3.053 .313 & 3,13 & 1.286 .980 & 5,5 & 25,5 & 19,0 & 48,0 \\
\hline Paraná & 399 & 81,4 & 9.563 .458 & 1,40 & 4.055 .739 & 20,1 & 22,3 & 17,1 & 39,1 \\
\hline
\end{tabular}

FONTE: IBGE (2008). Censo Demográfico. Dados trabalhados pelo autor.

Conforme se observa na Tabela 4, cerca de $81,4 \%$ da população paranaense se encontram nos centros urbanos. O elevado grau de urbanização está relacionado à concentração fundiária e à expansão das atividades agropecuárias com técnicas modernas de produção. Não obstante, observa-se a dinâmica do movimento da população ao longo da década de 1990, em que algumas mesorregiões sofreram redução na taxa de crescimento populacional, ao passo que outras sofreram elevação. Nesse sentido, a região metropolitana de Curitiba se apresenta com forte poder de atração populacional (com taxa média de crescimento populacional de 3,1\% ao longo da década de 1990). No interior do Estado, as mesorregiões Norte Central, Centro Oriental e Oeste, apresentaram taxas de crescimento populacional na ordem de $1,2 \%, 1,5 \%$ e $1,3 \%$, respectivamente. 
A maior concentração de população nessas mesorregiões ocorre em função da dinâmica urbana e pelo nível de atividade econômica, especialmente naqueles municípios que se caracterizam como pólos regionais. Entre eles se destacam: na mesorregião Norte Central, os municípios de Londrina e Maringá; na mesorregião Oeste, os municípios de Cascavel e Foz do Iguaçu; e, na mesorregião Centro Oriental, o município de Ponta Grossa. Nessas mesorregiões, apesar da importância da agropecuária, registram-se os menores percentuais de mão-de-obra ocupada nessa atividade. Isso se explica pela presença das agroindústrias e pelos serviços a ela associada e, por outro lado, pela tecnificação no meio rural. Por outro lado, nas áreas do Estado em que, por desvantagens da base física e tipo de solo para a exploração agrícola, o processo de modernização agropecuária tem inserção mais lenta, o seu esvaziamento é retardado. Essa realidade é a que se verifica nas mesorregiões Sudoeste, Centro Sul e Sudeste, onde a concentração populacional no meio rural é mais elevada.

De qualquer forma, com o esvaziamento da mão-de-obra do meio rural, quando ela se faz necessária é suprida com os, agora, "trabalhadores urbanos". Ou seja, o trabalhador vai de ônibus de linha ou fretado pelo empregador, motocicleta, entre outros pela manhã e volta à tarde. Não só o trabalhador, mas também os proprietários de terra, na grande maioria dos casos, não residem mais na propriedade rural. $\mathrm{Na}$ verdade, tem-se um movimento pendular do urbano para o rural. Em última análise, a terra é vista como um negócio, uma forma de valorizar o capital como outra atividade qualquer.

Ao analisar a distribuição da mão-de-obra ocupada verifica-se que o setor de serviços, em 2000, foi responsável por 39,1\% do emprego gerado no Paraná. O alto percentual de emprego gerado no setor de serviços justifica-se pela ampla rede de instituições que o Estado possui para atender à estrutura produtiva existente. Por sua vez, os setores agropecuário, industrial e de comércio estão nos mesmos patamares com aproximadamente $20,0 \%$ cada.

\section{CONCLUSÕES}

À guisa de conclusão, verificou-se que a RMC possui o núcleo forte da indústria paranaense, e a mesorregião Norte Central se caracteriza por concentrar os quatro principais agrupamentos agroindustriais do interior do Estado. Por sua vez, as mesorregiões Oeste e Sudoeste são as principais responsáveis pelo abate de aves, suínos e bovinos do Paraná. Diante do cenário apresentado anteriormente, observa-se que, mesmo com a concentração industrial na região metropolitana de Curitiba, a agroindústria paranaense se apresenta como fator de sustentação de grande parte das atividades econômicas do interior do Estado. Tal 
fato induz pensar que a agropecuária cresceu em resposta a esse ambiente favorável, pois se apresenta como importante fornecedora de matéria-prima para o processamento ao mesmo tempo em que demanda e gera serviços. Essa condição é verificada primeiro pela concentração da população nos centros urbanos e, segundo, na geração de emprego nas atividades do interior em relação à RMC.

\section{REFERÊNCIAS}

BULHÕES, R. Limites e possibilidades para expansão da cultura da soja no Paraná. 173 p. Tese (Doutorado em Economia Aplicada) - Instituto de Economia, Universidade Estadual de Campinas, Campinas, 2007.

CENSO AGROPECUÁRIO DE 1995-1996. Brasília: IBGE, 1995-1996. Disponível em: <http://www.ibge.gov.br/home/estatistica/economia/agropecuaria/censoagro/1995_1996/ default.shtm>. Acessso em 14/8/2008.

CUNHA, S.K.; CUNHA, J.C.; OLIVEIRA, M.A. Novo padrão de especialização da indústria paranaense nos anos 90. In: SEMINÁRIOS EM ADMINISTRAÇÃO FEA-USP - SEMEAD, 6., 2003, São Paulo. Anais... São Paulo: USP, 2003.

SISTEMA DE RECUPERAÇÃO AUTOMÁTICA - SIDRA. Brasília: IBGE. Disponível em: <http://www.sidra.ibge.gov.br/>. Acesso em: 14/8/2008.

PARANÁ: DIAGNÓSTICO SOCIAL E ECONÔMICO. Curitiba: IPARDES, 2003. Disponível em: <http://www.guaira.pr.gov.br/php/diag.pdf>. Acesso em 27/11/2008.

BASE DE DADOS DO ESTADO - BDEweb. Curitiba: IPARDES. Disponível em: < http://www.ipardes.gov.br/imp/index.php>. Acesso em 11/8/2008.

LOURENÇO, G. M. A economia paranaense nos anos 90: um modelo de interpretação. Curitiba: Ed. do Autor, 2000.

OLIVEIRA, M. A. Indústria paranaense na década de 1990: reestruturação e concentração. In: ENCONTRO DE ECONOMIA PARANAENSE, 2., 2003, Maringá. Anais... Maringá: UEM, 2003. p. 499-516. 